\title{
Analysis of Fracture Design in a Vertical Well with a Horizontal Fracture
}

\author{
Kai Dong ${ }^{\star}$, China National Petroleum Corporation, Beijing, China; Xiao Jin and Jie He, \\ Texas A\&M University, College Station, USA
}

\begin{abstract}
The overwhelming majority of hydraulic fractures are vertical and methods for designing them in both vertical and horizontal wells are well understood. In shallow and over-pressured formations there is a strong likelihood for horizontal fractures. Hence, horizontal fractures are common in shallow coalbed methane formations and may occur in highly over-pressured shale formations. Models for the transient flow and pressure behavior of horizontal fractures emanating from vertical wells exist and show highly distinct behavior from those for vertical fractures. Consequently, fracture design based on maximizing well productivity for a horizontally fractured well is distinct from the unified fracture design (UFD) strategies described previously for vertically-fractured vertical or horizontal wells.

This study shows well productivity behavior for horizontal fractures in homogeneous formations with or without vertical to horizontal permeability anisotropy as a function of suitably-defined proppant number, dimensionless fracture conductivity, and fracture penetration index parameters. For low penetration index, a relationship among fracture half-length, conductivity, and skin is provided.
\end{abstract}

This work provides a simple framework for horizontal fracture design.

\section{Introduction}

Hydraulic fracturing was first reported in the early 1950s (Grossman 1951) and has been extensively used to improve the well productivity in the oil and gas industry. Different fracturing techniques have been developed in the past 60 years, but the overwhelming majority of hydraulic fractures are vertical in the field practice, and the methods for designing them in both vertical and horizontal wells have been widely studied and well understood. The idea of horizontal fractures, however, does not receive much attention, and a limited volume of literature can be found about it in contrast to vertical fractures.

The application of horizontal fractures was greatly restricted because it was generally believed that in conventional reservoirs the vertical permeability is much lower than the horizontal (usually one tenth of the horizontal permeability), so that vertical fractures will be more beneficial than horizontal ones. Landrum and Crawford (1957) also found that horizontal fractures are not every effective in thick pays and if the well is not centered in the drainage area. A third reason is the old "common wisdom" (Gidley et al. 1989) that horizontal fractures cannot occur below 2,000 feet since the maximum stress direction is usually vertical, but Wright et al. (Wright et al. 1997) challenged it and reported a case of horizontal fractures at the depth of 7,500 feet due to high horizontal reservoir stress. There is another technical issue (Lowe and Huitt 1966) that proppants may deposit and form a dune around the wellbore in the horizontal fracture at high proppant concentration or low fluid velocity during the fracturing process, which is not likely for vertical fractures due to gravity. The dune will block the whole flow path and reduce the fracture flow capacity, resulting in shorter fracture length than designed.

Despite of these shortcomings of horizontal fractures, it has been recognized nowadays that horizontal fractures are far more common than generally believed. In fact, it was reported as early as in 1960 (Morrisson and Henderson 1960) that horizontal fractures were created to produce gravity drainage reservoirs. Horizontal fractures are also applicable to thin pays because of their low cost even though it has

Copyright (C) the author(s). This work is licensed under a Creative Commons Attribution 4.0 International License.

DOI: $10.14800 /$ IOGR.422

Received April 5, 2017; revised April 26, 2017; accepted May 4, 2017.

*Corresponding author: kai.dong@aliyun.com 
been shown by Sung et al. (Sung and Ertekin 1987) that horizontal wells have better performance. Moreover, horizontal fractures are common in unconventional reservoirs like shallow coal bed methane or heavy oil formations and highly over-pressured shale formations (Valko and Economidies 1998; Chhina et al. 1987; Britt et al. 2006). In addition, in-situ stress state change due to geological movements (e.g. a thrust fault) (Maxwell et al. 2007), secondary or enhanced oil recovery (Wright et al. 1997; Wong and Chau 2004) may result in significant growth of horizontal fractures during fracturing.

Daal and Economides (2006) studied hydraulically fractured wells in square and rectangular patterns, and they concluded that a dimensionless fracture conductivity of 1.6 will yield the highest productivity for production systems with proppant number below 0.1. Recently, Larsen (2011) did a type curve study of horizontal fractured wells in single and multilayer reservoirs. Their work brought up our interest in horizontal fractures and initialized this paper. We wanted to provide a simple framework for horizontal fracture design. And in our study we investigated well productivity behavior for horizontal fractures in homogeneous formations with or without vertical to horizontal permeability anisotropy as a function of suitably-defined proppant number, dimensionless fracture conductivity, and fracture penetration index parameters. We used the software Eclipse to build our models and run the simulation.

Upon completion of our simulation using our Eclipse model, we found that in a circular reservoir, the maximum $\mathrm{C}_{\mathrm{FD}}$ is no longer 1.6 but changes even at low proppant number below 0.1 . The maximum $\mathrm{J}_{\mathrm{D}}$ is also seen to be greater than $6 / \pi$ as seen in a square or rectangular reservoir. Upon doing sensitivity analysis, we also found that changing the effective radius increases the dimensionless productivity index at a constant value of dimensionless conductivity. Also, we found that by changing $\mathrm{Kv} / \mathrm{Kh}$, we are exponentially increasing the dimensionless production index.

\section{Model Description}

This section will introduce the model used in this work, its validity for this work, and data treatment after the simulation. Reservoir simulator Eclipse was used to build the model. After the model was set up, we run some known cases from other papers to verify our model. Finally, the calculation based on the simulated data was introduced.

Model for Simulation. The model used is a radial reservoir, with a well fully penetrating the formation right in the center. The fracture is created as radial fracture, with the radius of $r_{\mathrm{f}}$. This model is shown in Figure 1.

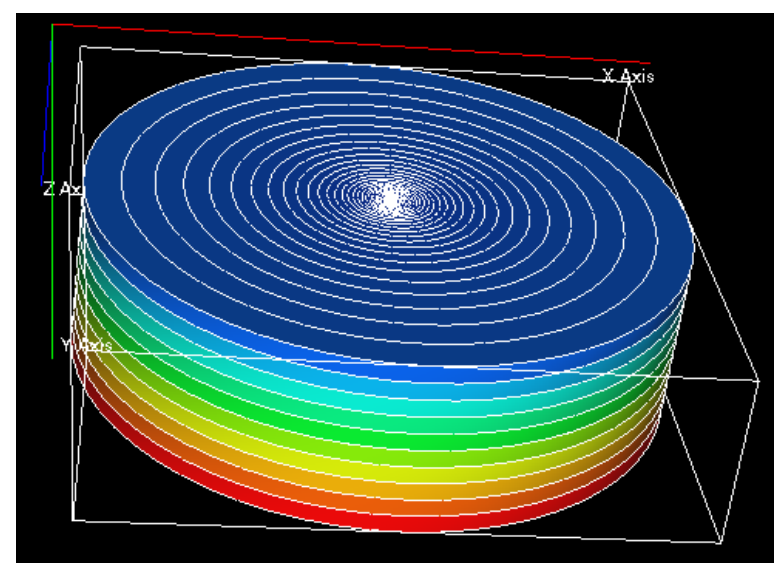

Figure 1-Reservoir model with fracture.

In Figure 1, different colors represent different layers. In this model, we divide the formation into 11 layers, with one layer containing the horizontal fracture. The horizontal fracture is contained in the middle layer. Note that only 10 layers can be observed in Figure 1 as the middle layer is too thin to be observed. If we make the middle layer thicker, shown in Figure 2, the layer with fracture can be seen, but this is just for illustration. In the model calculation, the middle layer is assigned to a very small thickness. 


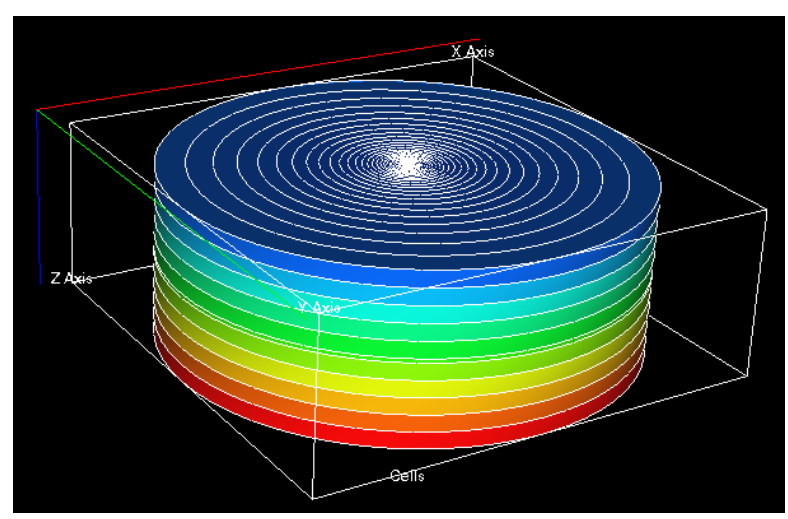

Figure 2-Reservoir model with visible fracture in the middle layer.

Radial coordinated was used for this theoretical model. The radial direction is discretized into 50 grids, theta direction is treated as one grid, and vertical direction is discretized into 11 even grids. The algorithm for discretizing radius is Eq. 1,

$$
\frac{R_{i}}{R_{i-1}}=\left(\frac{R_{e}}{R_{i-1}}\right)^{(i-1) / n}
$$

In this equation, $i$ is the grid number in radial direction while $n$ is the total grid number in radial direction, which is 50 in this case.

The fracture is treated by changing the layer thickness and grid permeability and porosity. The desired grid permeability can be calculated by the Eq. 2 which provides the proppant number and reservoir properties.

$$
N_{p-H F}=\frac{k_{f} w r_{f}}{k_{v} r_{e}^{2}}
$$

Note that in our model, the fracture width is not calculated but selected by us. As the fracture permeability need to be set a reasonable value, neither too large nor too small, to avoid simulation failure. And we can see, inside the fracture, the permeability is different in different radial grids.

In our simulator, we assigned the whole layer with the same thickness as fracture width. The fracture may not necessarily penetrate fully the whole formation, so that each layer has two different permeability and porosity, with inner part for the fracture and outer part for the reservoir.

Model Verification. Since we treat the hydraulic fracture as formation with high permeability, porosity and tiny width, we need to verify whether this method is appropriate or not. This part provides the simulated results for a horizontal fracture in a large reservoir. The input data is from Larsen (2011).

After the simulation, the flowing bottom-hole-pressure with time can be exported. Thus a log-log diagnostic plot can be generated as shown in Figure 3. This graph is consistent with the graph in Larsen's paper (2011). In conclusion, the model can be used to simulate the horizontal fracture. 


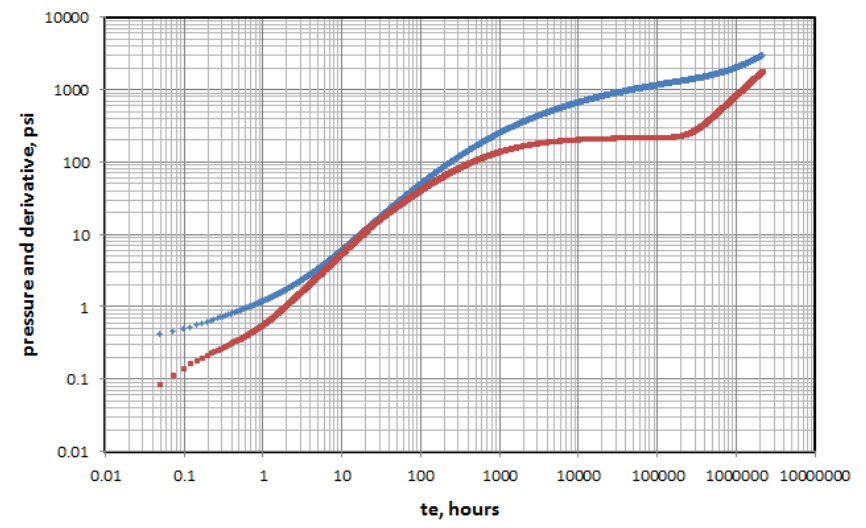

Figure 3-Simulated log-log diagnostic plot based on Larsen's input.

Calculation Based on the Simulated Data. The methods for calculating the dimensionless productivity index and dimensionless horizontal fracture conductivity are illustrated in this part.

The dimensionless horizontal fracture conductivity measures the relative ease of the fluid flowing from reservoir to fracture and then to the wellbore. It can be calculated as Eq. 3.

$$
C_{f D-H F}=\frac{k_{f} w}{k_{v} r_{f}},
$$

$C_{f D-H F}$ has the following relationship with proppant number. Provided a fixed fracture radius and drainage area radius, the dimensionless horizontal fracture conductivity is proportional with the proppant number.

$$
N_{p-H F}=\frac{k_{f} w r_{f}}{k_{v} r_{e}^{2}}=\frac{k_{f} w}{k_{v} r_{f}} \cdot \frac{r_{f}^{2}}{r_{e}^{2}}=C_{f D-H F}\left(\frac{r_{f}}{r_{e}}\right)^{2}
$$

After the model was set up, we can easily calculated $C_{f D-H F}$ as we know the reservoir properties and simulation fracture properties. The dimensionless well conductivity is defined as Eq. 5.

$$
J_{D}=\frac{141.2 B \mu}{k h} J
$$

After each simulation, the average reservoir pressure $p_{\text {ave, }}$ and flowing bottom-hole-pressure, $p_{\mathrm{wf}}$ can be obtained. Thus, the well productivity can be calculated as Eq. 6.

$$
J=\frac{Q}{p_{\text {ave }}-p_{w f}}
$$

\section{Results Analysis}

In order to achieve our goal of analyzing horizontal fractures in homogenous formations with a vertical well as a function of proppant number, dimensionless fracture conductivity, and fracture penetration index parameters, Eclipse was used to design the model. The following sections will include the actual problem statement, reservoir properties of the formation which are the inputs of our Eclipse model. And we will take an in-depth look at nine different cases of $\mathrm{J}_{\mathrm{D}}$ versus $\mathrm{C}_{\mathrm{fD}} \mathrm{HF}$ with changes in $\mathrm{N}_{\mathrm{p}-\mathrm{HF}}, \mathrm{xe} / \mathrm{h}$, and also differences in isotropic and anisotropic reservoirs.

Problem Statement. Given a specific set of reservoir properties for designing a vertical well with horizontal fractures, we analyzed the scenario of JD versus $\mathrm{C}_{\mathrm{fD}-\mathrm{HF}}$. Table 1 describes the reservoir properties we used to design the problem solution. 
Table 1-Reservoir properties for model analysis.

\begin{tabular}{|c|c|c|}
\hline Parameters & Values & Units \\
\hline$p_{\mathrm{i}}$ & 3000 & $\mathrm{psi}$ \\
\hline $\mathrm{r}_{\mathrm{w}}$ & 0.3 & $\mathrm{ft}$ \\
\hline$\phi$ & 0.1 & $\mathrm{cp}$ \\
\hline$\mu$, & 1 & $1 / \mathrm{psi}$ \\
\hline$c_{\mathrm{t}}$ & $13.10^{*} 10^{-6}$ & $\mathrm{ft}$ \\
\hline $\mathrm{nf}$ & 1 & \\
\hline$x_{\mathrm{f}}$ & 200 & \\
\hline$S$ & 0 & \\
\hline
\end{tabular}

Case Analysis. There are nine different cases for analysis using the reservoir model designed in Eclipse as shown in Table 2.

Table 2-Cases Designed for Eclipse Model.

\begin{tabular}{|c|c|c|}
\hline Case 1 & $\mathrm{k}_{\mathrm{v}} / \mathrm{k}_{\mathrm{h}}=0.1$ & $\mathrm{x}_{\mathrm{e}} / \mathrm{h}=10$ \\
\hline Case 2 & $\mathrm{k}_{\mathrm{v}} / \mathrm{k}_{\mathrm{h}}=0.1$ & $\mathrm{x}_{\mathrm{e}} / \mathrm{h}=20$ \\
\hline Case 3 & $\mathrm{k}_{\mathrm{v}} / \mathrm{k}_{\mathrm{h}}=0.1$ & $\mathrm{x}_{\mathrm{e}} / \mathrm{h}=50$ \\
\hline Case 4 & $\mathrm{k}_{\mathrm{v}} / \mathrm{k}_{\mathrm{h}}=1$ & $\mathrm{x}_{\mathrm{e}} / \mathrm{h}=10$ \\
\hline Case 5 & $\mathrm{k}_{\mathrm{v}} / \mathrm{k}_{\mathrm{h}}=1$ & $\mathrm{x}_{\mathrm{e}} / \mathrm{h}=20$ \\
\hline Case 6 & $\mathrm{k}_{\mathrm{v}} / \mathrm{k}_{\mathrm{h}}=1$ & $\mathrm{x}_{\mathrm{e}} / \mathrm{h}=50$ \\
\hline Case 7 & $\mathrm{k}_{\mathrm{v}} / \mathrm{k}_{\mathrm{h}}=10$ & $\mathrm{x}_{\mathrm{e}} / \mathrm{h}=10$ \\
\hline Case 8 & $\mathrm{k}_{\mathrm{v}} / \mathrm{k}_{\mathrm{h}}=10$ & $\mathrm{x}_{\mathrm{e}} / \mathrm{h}=20$ \\
\hline Case 9 & $\mathrm{k}_{\mathrm{v}} / \mathrm{k}_{\mathrm{h}}=10$ & $\mathrm{x}_{\mathrm{e}} / \mathrm{h}=50$ \\
\hline
\end{tabular}

Among the cases we have cases four, five, six being isotropic cases and cases one, two, three, seven, eight, nine being anisotropic cases. To fully understand the plot it is possible to use a sensitivity analysis with variation of $\mathrm{x}_{\mathrm{e}} / \mathrm{h}, \mathrm{k}_{\mathrm{v}} / \mathrm{k}_{\mathrm{h}}$, and different proppant numbers. We observed the effect of proppant number (NP-HF) on dimensionless well conductivity (JD) at different dimensionless horizontal fracture conductivity (CFD-HF) in Case 7 (Figure 4). As we increase the proppant number, we also increase JD-HF opt, and CFD-HF opt. While it is a great thing to increase the productivity index to as high as possible, it might not be the most efficient way to design the treatment because increasing the proppant number costs money. 


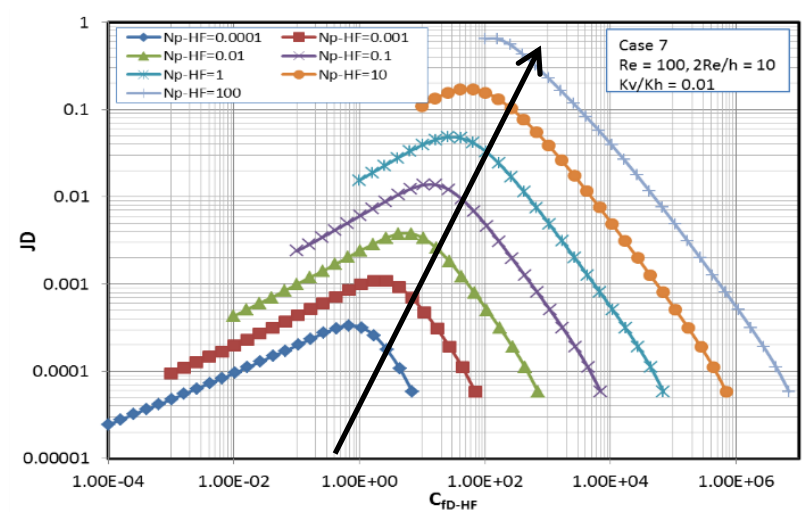

Figure 4-Case 7 with $k_{v} / k_{h}=10$ and proppant number from 0.00001 to 100 .

With a skin factor of zero, the effective radius $r_{e}$ is the same as the wellbore radius $r_{w}$. As we are increasing the effective radius, we are also increasing the dimensionless productivity index at every value of dimensionless conductivity. This is shown in Figure 5 as we look at a sensitivity analysis of with different values of $r_{e}$. This makes sense because as we have more effective radius holding the permeability constant, we will have more production due to the increase drainage area.

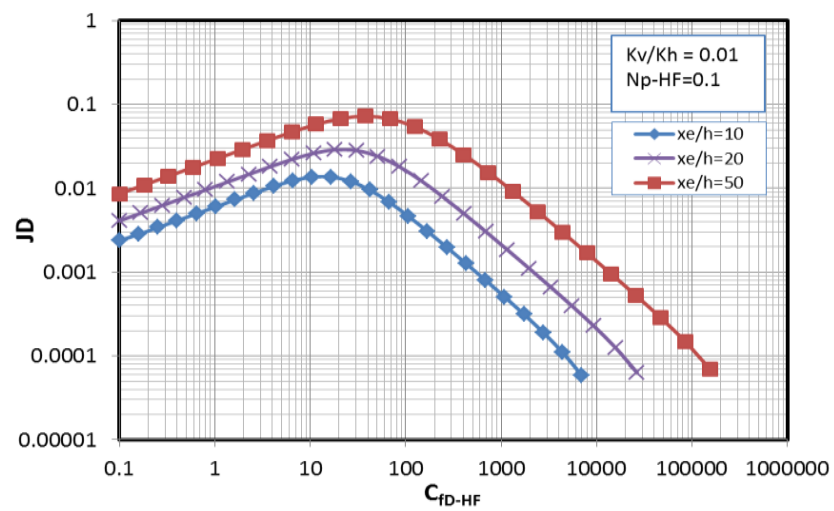

Figure 5-Sensitivity Analysis with varying values of effective radius.

The increase in $\mathrm{k}_{\mathrm{v}} / \mathrm{k}_{\mathrm{h}}$ versus $\mathrm{J}_{\mathrm{D}}$ is an exponential increase. This is important because in designing a reservoir to maximize $J_{D}$ to minimize proppant cost, we want to have a higher $\mathrm{k}_{\mathrm{v}} / \mathrm{k}_{\mathrm{h}}$ ratio while increasing the dimensionless conductivity. As shown in Figure 6, a sensitivity analysis of $\mathrm{k}_{\mathrm{v}} / \mathrm{k}_{\mathrm{h}}$ by a power of 10 .

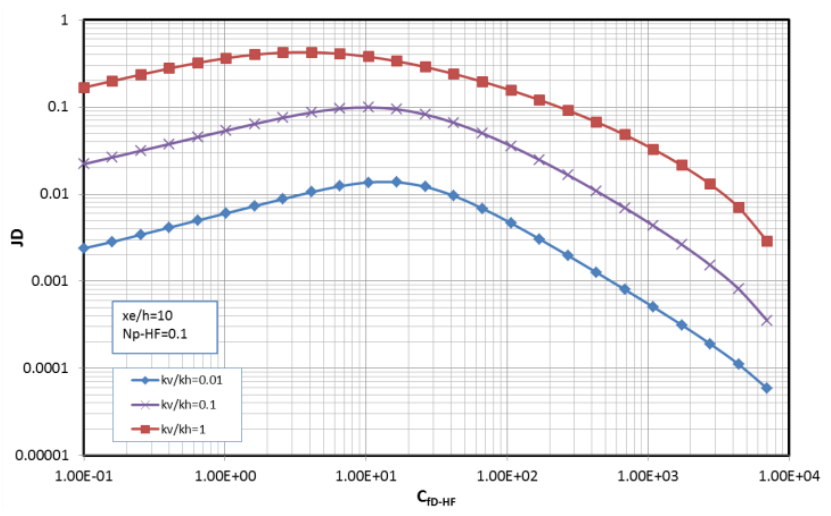

Figure 6-Sensitivity Analysis with varying $k_{v} / k_{h}$ ratio.

The consistency with all case scenarios shown in the Appendix (Figures 7 through 14) also proves the importance of designing with the optimum $\mathrm{k}_{\mathrm{v}} / \mathrm{k}_{\mathrm{h}}$ ratio in mind as it has the greatest effect on the productivity index. Knowing the optimum dimensionless conductivity $\left(\mathrm{C}_{\mathrm{FD}}\right)$ also makes the hydraulic fracture stimulation more cost-effective to enhance production due to reducing unnecessary proppant. 


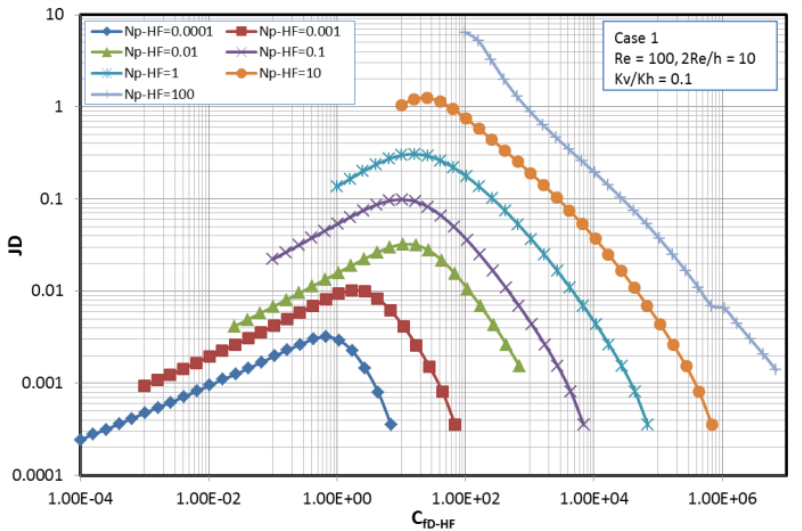

Figure 7-Case 1 with $x_{e} / h=10$ and $k_{v} / k_{h}=0.1$.

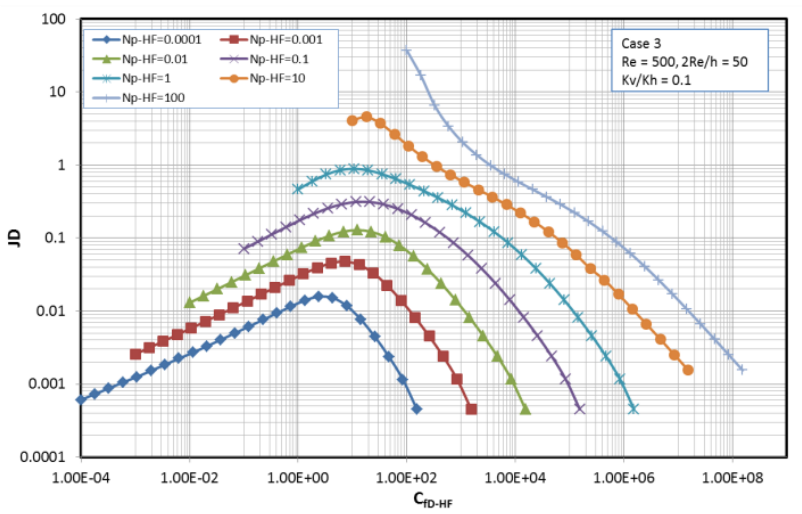

Figure 9-Case 3 with $x_{e} / h=50$ and $k_{v} / k_{h}=0.1$.

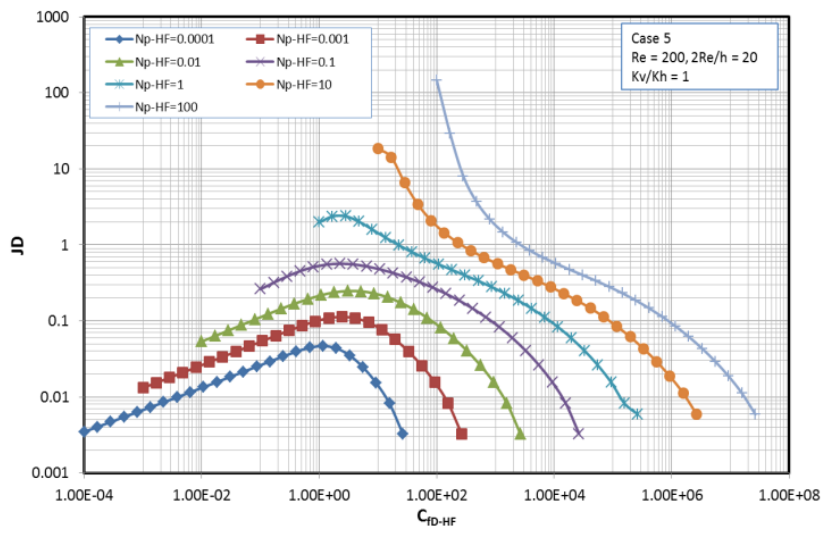

Figure 11-Case 5 with $x_{e} / h=20$ and $k_{v} / k_{h}=1$.

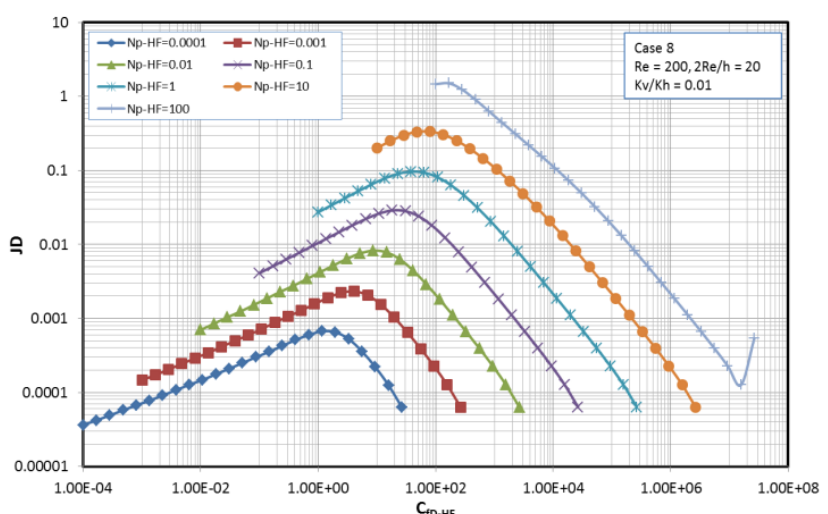

Figure 13-Case 8 with $x_{e} / h=20$ and $k_{v} / k_{h}=0.01$.

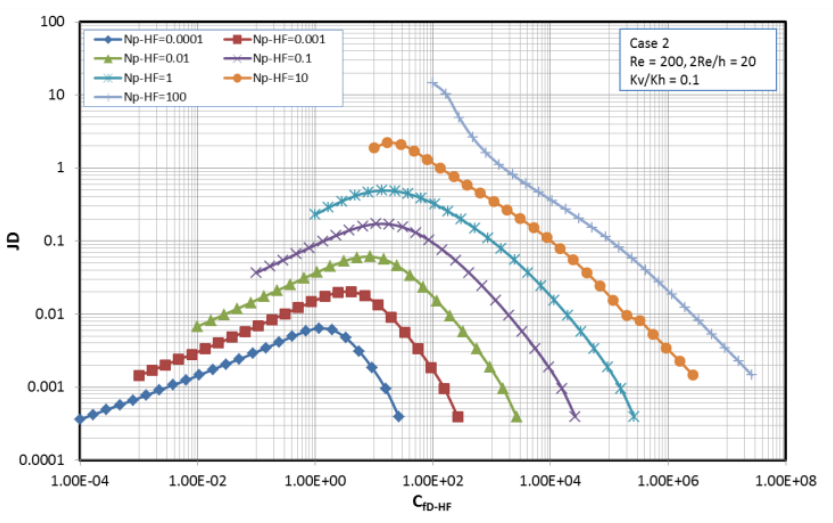

Figure 8-Case 2with $x_{e} / h=20$ and $k_{v} / k_{h}=0.1$.

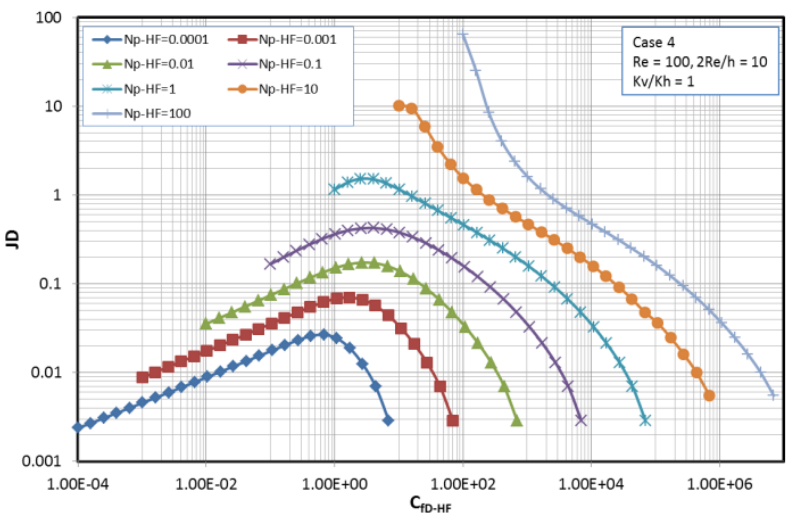

Figure 10-Case 4 with $x_{e} / h=10$ and $k_{v} / k_{h}=1$.

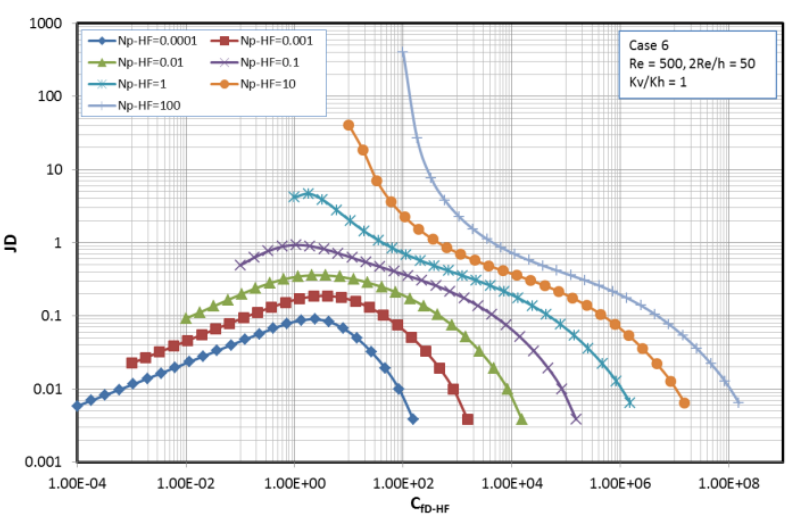

Figure 12-Case 6 with $x_{e} / h=50$ and $k_{v} / k_{h}=1$.

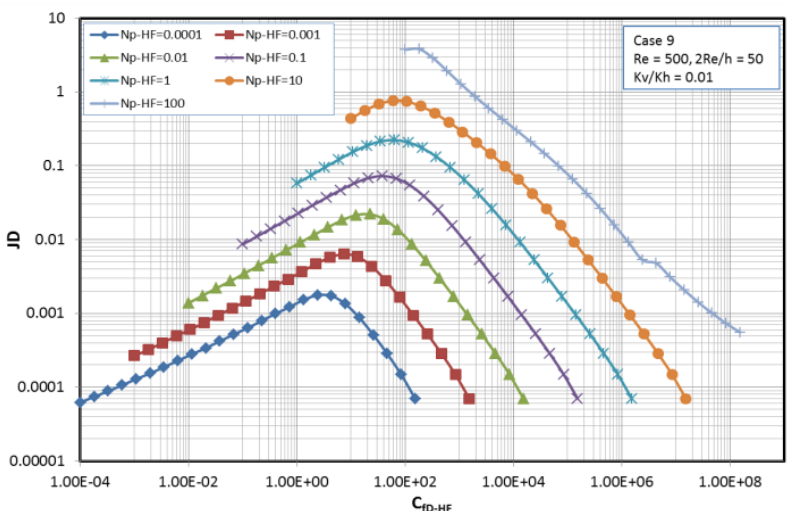

Figure 14-Case 9 with $x_{e} / h=50$ and $k_{v} / k_{h}=0.01$. 


\section{Conclusions}

1. At a higher proppant number we will see a higher dimensionless productivity index at every value of conductivity

2. In order to maximize productivity we need maximum the effective drainage radius.

3. We want a higher $\mathrm{k}_{\mathrm{v}} / \mathrm{k}_{\mathrm{h}}$ ratio when producing in a vertical well with a horizontal fracture to minimize cost of proppant.

\section{Nomenclature}

$\begin{aligned} \mathrm{B} & =\text { formation volume factor, } \mathrm{rb} / \mathrm{STB} \\ \mathrm{CfD}-\mathrm{HF} & =\text { dimensionless horizontal fracture conductivity } \\ \mathrm{h} & =\text { formation height, } \mathrm{ft} \\ \mathrm{HF} & =\text { horizontal fracture } \\ \mathrm{J} & =\text { well productivity index, } \mathrm{STB} / \mathrm{D} / \mathrm{psi} \\ \mathrm{JD} & =\text { dimensionless well productivity index } \\ \mathrm{k}_{\mathrm{f}} & =\text { fracture permeability, md } \\ \mathrm{k}_{\mathrm{v}} & =\text { formation vertical permeability, md } \\ \mathrm{k}_{\mathrm{h}} & =\text { formation horizontal permeability, } \mathrm{md} \\ \mu & \text { fluid viscosity, } \mathrm{cp} \\ \mathrm{Np}-\mathrm{HF} & =\text { horizontal fracture proppant number } \\ \mathrm{p}_{\mathrm{ave}} & =\text { average reservoir pressure, } \mathrm{psi} \\ \mathrm{p}_{\mathrm{wf}} & =\text { bottom hole flowing pressure, } \mathrm{psi} \\ \mathrm{Q} & =\text { production rate, } \mathrm{STB} / \mathrm{D} \\ \mathrm{r}_{\mathrm{i}} & =\text { radial position of } \mathrm{i} \text {-th grid, } \mathrm{ft} \\ \mathrm{r}_{\mathrm{e}} & =\text { reservoir radius, } \mathrm{ft} \\ \mathrm{r}_{\mathrm{f}} & =\text { fracture radius, } \mathrm{ft} \\ \mathrm{w} & =\text { fracture width, } \mathrm{ft}\end{aligned}$

\section{Acknowledgement}

We would like to express our gratitude to Dr. Christine Ehlig-Economides, Professor of Petroleum Engineering at Texas A\&M University, for her continuous guidance and invaluable advice in our preparation of this paper. We would also like to thank Kappa Engineering and Schlumberger for providing the software Ecrin and Eclipse, without which this study would not have been possible, as well as our classmates in course PETE 648 Pressure Transient Testing SU2012 for sharing their data with us.

\section{Conflicts of Interest}

The author(s) declare that they have no conflicting interests.

\section{References}

Britt, L. K., Dunn-Norman, S., Smith, M. B, et al. 2006. Characterization of a Shallow Horizontal Fracturing Treatment in Western Missouri. Paper presented in SPE Annual Technical Conference and Exhibition, San Antonio, Texas, USA, 24-27 September. SPE-102342-MS.

Chhina, H.S., Luhning, R.W., Bilak, R.A., et al. 1987. A Horizontal Fracture Test in the Athabasca Oil Sands. Paper presented in Annual Technical Meeting, Calgary, Alberta, 7-10 June. PETSOC-87-38-56.

Daal, J. A. and Economides, M. J. 2006. Optimization of Hydraulically Fractured Wells in Irregularly Shaped Drainage Areas. Paper presented in International Symposium and Exhibition on Formation Damage Control, Lafayette, Louisiana, USA. 15-17 February. SPE-98047-MS.

Gidley, J. L., Holditch, S. A., Nierode, D. E., et al. 1989. Recent Advances in Hydraulic Fracturing. Monograph Series: 12.

Grossman, W. L. 1951. Hydrafrac Operations in the Spraberry Production, West Texas. Paper presented in Fall Meeting of the Petroleum Branch of AIME, Oklahoma City, Oklahoma, 3-5 October. SPE-128-G. 
Landrum, B. L. and Crawford, P. B. 1957. Estimated Effect of Horizontal Fractures in Thick Reservoirs on Pattern Conductivity. Journal of Petroleum Technology 9(10):50-52.

Larsen, S. L. 2011. Horizontal Fractures in Single and Multilayer Reservoirs. Paper presented in Canadian Unconventional Resources Conference. Society of Petroleum Engineers, Alberta, Canada, 15-17 Novemer. SPE147004-MS.

Lowe, D. K. and Huitt, J. L. 1966. Propping Agent Transport in Horizontal Fractures. Journal of Petroleum Technology 18(6): 753-764. SPE-1285-PA

Maxwell, S. C., Zimmer, U., and Gusek, R.W. 2007. Evidence of Horizontal Hydraulic Fracture at Depth Due to Stress Rotations Across a Thrust Fault. Paper presented in SPE Annual Technical Conference and Exhibition, Anaheim, California, USA, 11-14 November. SPE-110696-MS.

Morrisson, T. E. and Henderson, J. H. 1960. Gravity Drainage of Oil Into Large Horizontal Fractures. SPE J 219(1):20-25.SPE-1330-G.

Sung, W. and Ertekin, T. 1987. Performance Comparison of Vertical and Horizontal Hydraulic Fractures and Horizontal Boreholes in Low Permeability Reservoirs: A Numerical Study. Paper presented in Low Permeability Reservoirs Symposium, Denver, Colorado, USA, 18-19 May. SPE-16407-MS.

Wright, C. A., Davis, E., Weijers, L., et al. 1997. Horizontal Hydraulic Fractures: Oddball Occurrences or Practical Engineering Concern? Paper presented at SPE Western Regional Meeting, Long Beach, California, USA, 25-27 June. SPE-38324-MS.

Wong, R. and Chau K. 2004. Propagation of In Situ Horizontal Fractures in Shale Due to Steam Injection. Journal of Canadian Petroleum Technology 43(1):41-46.

Valko, P. P. and Economidies, M. J. 1998. Heavy Crude Production from Shallow Formations: Long Horizontal Wells Versus Horizontal Fractures. Paper presented in SPE International Conference on Horizontal Well Technology, Calgary, ALberta, Canada, 1-4 November. SPE-50421-MS.

Kai Dong is a production engineer at China National Petroleum Corporation (CNPC) in Beijing, working on shale gas reservoirs in southwest China. Before joining CNPC, he worked as a production technologist with Baker Hughes, Houston. Dong's specialties and research interests include well stimulation in all kinds of reservoirs, well-performance optimization and general production engineering. $\mathrm{He}$ is an active SPE member. Dong holds a bachelor's degree in petroleum engineering from China University of Petroleum, Beijing, and master's and Ph.D degrees in petroleum engineering from Texas A\&M University.

Jie He is a quantitative associate at Wells Fargo. Before joining Wells Fargo, he worked as a research intern at Halliburton. He specializes in computational mathematics and reservoir simulation. He holds a BE in Chemical Engineering from Tsinghua University, an MS in Chemical Engineering from Washington University in St. Louis, and a PhD in Petroleum Engineering from Texas A\&M University.

Xiao Jin is a Ph.D. candidate currently studying Petroleum Engineering at Texas A\&M University. Previously, he has worked full-time for Baker Hughes, a GE Company as a hydraulic fracturing engineer and interned with ExxonMobil Upstream Research Company as an unconventional research engineer. Jin has authored and co-authored 4 technical papers and currently serve as a technical editor for the SPE Journal. His research interests include hydraulic fracturing and matrix acidizing. He also obtained both B.S. and M.S. degrees all in Petroleum Engineering at Texas A\&M University. Jin is a member of SPE. 